\title{
Vídeos como objetos de aprendizagem potencialmente significativos
}

\author{
Adriano Edo Neuenfeldt*, Rogério José Schuck ${ }^{\star \star}$, Lara Kalkmann Goulart ${ }^{\star \star \star}$
}

\section{Resumo}

Este artigo versa sobre a produção de vídeos como objetos de aprendizagem potencialmente significativos (Oaps). Os vídeos foram postados num canal do YouTube gerenciado pelos próprios estudantes. Com o trabalho desenvolvido, buscaram-se analisar e apontar alternativas metodológicas, para incluir os estudantes nos processos de ensino e de aprendizagem. Foi desenvolvido um estudo de caso que envolveu estudantes matriculados na disciplina de cálculo de uma instituição do ensino superior. Ressalta-se que a proposta permanece em desenvolvimento e, até o momento, foi possivel perceber que os estudantes se comportam, principalmente, como consumidores de informação e, em menor escala, como produtores de conhecimento, tendo o professor como mediador do processo.

Palavras-chave: Aprendizagem significativa. Objetos de aprendizagem. Vídeos.

\section{Introdução}

Na contemporaneidade, é possível observar a presença das tecnologias digitais na maioria das salas de aula do ensino superior. No entanto, ainda se percebe certa ressalva à sua inclusão nas metodologias utilizadas por docentes. Diante disso, percebeu-se um nicho de exploração em torno do uso das tecnologias digitais, e buscaram-se analisar e organizar possíveis estratégias de ensino e de aprendizagem que envolvessem essas tecnologias.

Para atingir os objetivos da proposta, realizou-se uma pesquisa prévia com estudantes matriculados na disciplina de

Doutorando em Ensino no Programa de Pós-Graduação em Ensino (PPGEnsino), Universidade do Vale do Taquari. E-mail: adrianoneuenfeldt@univates.br

* Doutor em Filosofia pela Pontifícia Universidade Católica do Rio Grande do Sul. Docente do Programa de Pós-Graduação em Ensino, Universidade do Vale do Taquari. E-mail: rogerios@univates.br

*** Acadêmica de Psicologia, Universidade do Vale do Taquari. E-mail: lara.goulart@univates.br 
cálculo de cursos de engenharia de uma instituição de ensino superior do Rio Grande do Sul. Objetivou-se verificar as dificuldades quanto aos conteúdos e à acessibilidade às tecnologias e à internet, para posteriormente lançar uma proposta de quebra de paradigmas, tornando os alunos parte dos processos de ensino e de aprendizagem, incorporando, nesse processo, as tecnologias digitais.

Nessa perspectiva, cada um dos vídeos produzidos configurou-se como um objeto de aprendizagem potencialmente significado (Oaps). Procurou-se incorporar conceitos e características a respeito de objetos de aprendizagem a partir de Wiley (2000), Audino e Nascimento (2010), Tarouco et al. (2014), Braga (2014), entre outros, e, a respeito da produção de significados, a partir de Ausubel (1963) e de Moreira e Massoni (2016). Ao final, os materiais produzidos permaneceram à disposição em um canal do YouTube gerenciado pelos próprios estudantes.

Também se integrou ao quadro de discussão o contexto das tecnologias digitais de informação e comunicação (Tdics) e a cultura e o espaço em que os jovens estão imersos, quais sejam, cibercultura e ciberespaço. Nesse viés, encontraram-se autores que refletem sobre o tema e que auxiliaram nesta escrita, como Lévy (2010a, 2010b, 2015), que descreve o ciberespaço como "o espaço aberto pela interconexão mundial dos computado- res e das memórias dos computadores" (LÉVY, 2010a, p. 94), e Santaella (2004), segundo o qual

[...] o universo virtual das redes alastrou-se exponencialmente por todo o planeta fazendo emergir um universo paralelo ao universo físico no qual nosso corpo se move (SANTAELLA, 2004, p. 39).

Esclarece-se que a proposta se encontra em aplicação, e, portanto, os dados ainda estão sendo coletados. Contudo, almeja-se aprimorar os processos de ensino e de aprendizagem, repensando a prática docente e a inclusão ativa dos estudantes nesses processos.

\section{Contextualizando a proposta}

Este estudo é o recorte de uma investigação que iniciou no primeiro semestre de 2016 e está em andamento, sendo desenvolvida com estudantes do ensino superior de uma instituição no Vale do Taquari, RS, na sua maioria pertencentes a cursos de engenharia.

Os objetivos da proposta foram e ainda são analisar e compreender os impactos que a produção de vídeos como Oaps poderia causar na aprendizagem desses alunos durante os processos de ensino e de aprendizagem, no decorrer das aulas desenvolvidas por um professor da instituição.

Neste trabalho, focaliza-se, especificamente, uma turma da disciplina de Cálculo II do segundo semestre de 2017. 
Ressalta-se que, dos 44 estudantes que compunham a turma, 35 participaram da proposta, divididos em 12 grupos com, no máximo, quatro integrantes. $\mathrm{O}$ índice de adesão foi considerável, uma vez que a proposta foi executada em horário alternativo, ou seja, fora da sala de aula e de modo voluntário.

Quanto à abordagem, a investigação teve foco quantitativo, pois, nos questionários aplicados, foram coletados dados numéricos, que foram organizados em forma de gráficos. Também se caracterizou como uma abordagem qualitativa, em que os pesquisadores "privilegiam, essencialmente, a compreensão dos comportamentos a partir da perspectiva dos sujeitos da investigação" (BOGDAN; BIKLEN, 1994, p. 16), uma vez que se acompanharam, durante as aulas, os relatos dos estudantes quanto ao desenvolvimento da proposta e os comentários inseridos nos questionários. Quanto aos questionários, foram desenvolvidos no Google Drive, para que, posteriormente, as respostas fossem tabuladas e categorizadas, utilizando a técnica da Análise Textual Discursiva (MORAES; GALIAZZI, 2013).

\section{Impressões iniciais e organização da proposta}

Diante das dificuldades de compreensão teórica dos conteúdos referentes à disciplina de Cálculo II percebidas em uma turma de uma instituição de ensino superior, realizou-se um questionário no Google Drive para auxiliar a compreensão desse problema.

Dentre as diversas questões apresentadas pelos alunos nesse questionário, constatou-se que os conteúdos que geravam mais dificuldades e eram considerados difíceis pelos estudantes diziam respeito a integrais e derivadas. Esses conteúdos já haviam sido desenvolvidos na disciplina de Cálculo I, desenvolvida no semestre anterior, o que levou a inferir que, mesmo os alunos tendo sido aprovados, permaneciam com dúvidas.

Também foi possível elencar, a partir do diálogo com os estudantes, motivos da dificuldade de aprendizagem. Elencaram-se alguns pontos para que os alunos os classificassem de acordo com a ordem de importância. Os estudantes poderiam assinalar até três opções. Constatou-se que as maiores dificuldades estavam no conteúdo, considerado difícil. Esse fator se somou principalmente à pouca dedicação e à falta de tempo para estudar.

Na sequência, buscou-se descobrir se os estudantes procuravam formas para complementar seus estudos. Percebeu-se, por exemplo, que eles consultavam, com certa regularidade, vídeos on-line, para auxiliar na aprendizagem dos conteúdos desenvolvidos em aula, ou seja, aproximadamente $40 \%$ dos estudantes acessavam a internet com esse fim de uma a cinco vezes por semana. Porcen- 
tagem similar acessava pelo menos uma vez por semana. Também foi possível observar que a maioria dos estudantes tinha um comportamento passivo, ou seja, apenas assistia aos vídeos, sendo que $83 \%$ nunca haviam produzido um vídeo.

Desse modo, iniciou-se a configuração da proposta na forma de um desafio, uma vez que todos tinham disponíveis tecnologias capazes de produzir vídeos. Para sistematizar melhor o processo, ele foi dividido em quatro fases, a saber: fase 1 - análise de um vídeo pronto; fase 2 - elaboração, pelo grupo, de um novo vídeo; fase 3 - avaliação do vídeo produzido pelo grupo e apresentação da produção para a turma; e fase 4 - ajustes e postagem num canal do YouTube.

\section{Fase 1: análise de um vídeo pronto}

Considerando que as dificuldades de conteúdos estavam relacionadas à disciplina de Cálculo I do semestre anterior, especificamente aos conteúdos de derivadas e integrais, solicitou-se a análise de um vídeo produzido por alunos de outra turma. A atividade, embora fosse realizada em grupo, exigiu dedicação individual de cada membro do grupo. A análise foi realizada mediante um questionário enviado pelo Google Drive, levando em conta aspectos como: domínio do conteúdo; clareza das explicações; criatividade; edição e recursos utilizados; envolvimento; e tempo utilizado pela equipe na organização do vídeo. Também houve um espaço para discutir contribuições aos vídeos analisados.

\section{Fase 2: organização e produção de um vídeo}

Nesta fase, os grupos se reuniram e produziram seus vídeos de acordo com as tecnologias de que dispunham, fossem celulares, computadores ou, mesmo, câmeras filmadoras disponibilizadas pela instituição. A escolha dos conteúdos ficou a cargo dos estudantes; no entanto, foi-lhes solicitado um relatório no qual deveria constar a questão desenvolvida, os apontamentos a respeito das tecnologias, as referências utilizadas, bem como um relato resumido de todo o processo de organização da produção.

\section{Fase 3: avaliação e apresentação do vídeo produzido pelo grupo}

Após o vídeo estar finalizado, solicitou-se que os estudantes avaliassem o material produzido por eles. Para tanto, responderam um questionário no Google Drive com critérios semelhantes aos utilizados na avaliação do vídeo de outra turma. O processo complementou-se a partir da apresentação dos trabalhos para a turma em momento de aula. $\mathrm{Na}$ data escolhida, toda a turma participou 
da avaliação, sugerindo melhorias ou destacando virtudes dos vídeos.

Fase 4: ajustes e postagem

Depois de o grupo ter assentido ou não com os possíveis ajustes sugeridos pela turma, o vídeo foi disponibilização num canal do YouTube, a saber: As Várias Matemáticas. Os estudantes são os responsáveis pelo canal e autorizaram a postagem dos vídeos.

Cabe destacar que o professor, no processo descrito, atuou apenas como mediador, sugerindo ajustes quando fosse o caso, estando livre os estudantes para fazê-los ou não. Como se trata de um processo contínuo, equívocos conceituais ou de aspectos técnicos podem ocorrer, mas eles são resolvidos à medida que os semestres transcorrem. A proposta também tem como objetivo melhorar a partir de erros, das discussões geradas, abrindo oportunidade no canal para postagem de comentários.

\section{Referencial teórico}

A priori, organiza-se o referencial teórico a partir de três eixos: o primeiro trata da criação dos Oaps; o segundo diz respeito às relações estabelecidas na contemporaneidade a partir da cibercultura e do ciberespaço com uso do YouTube como repositório de vídeos; e o terceiro refere-se ao papel do professor como mediador do processo.

\section{Objetos de aprendizagem potencialmente significativos}

Não se trata de tarefa árdua encontrar vídeos explicativos de conteúdos relativos às ciências exatas, mais especificamente à disciplina de cálculo. Contudo, percebem-se também o cunho comercial desses vídeos e o fato de muitas páginas considerarem o conteúdo do vídeo como acabado, não abrindo espaço para que os estudantes possam opinar sobre o conteúdo.

Diante disso, almejou-se possibilitar aos estudantes a construção do seu próprio material. Partiu-se do pressuposto de que eles deveriam estar dispostos a querer aprender e aprender mediante conhecimentos prévios. Isso levou à exploração de conceitos condizentes com a aprendizagem significativa de Ausubel (1963) e de Moreira e Massoni (2016).

Entendeu-se que cada material produzido pelos estudantes deveria se configurar como um objeto de aprendizagem, contendo as características exploradas nas obras de Wiley (2000), Tarouco et al. (2014) e Braga (2014). Conforme Wiley, um objeto de aprendizagem pode ser definido como "any entity, digital or non-digital, which can be used, re-used or referenced during technology supported learning" (2000, p. 4).

Algumas características podem ser observadas na produção dos vídeos articulados como objetos de aprendizagem. 
Dentre elas, ressaltam- se: a reutilização; a adaptabilidade; a granularidade; a acessibilidade; a durabilidade; e a interoperabilidade (AGUIAR; FLÔRES, 2014).

No entanto, percebeu-se que o conceito de objeto de aprendizagem aplicado à organização de vídeos poderia ser ampliado, incorporando a produção de significados. Para tanto, uma vez que esses vídeos também trataram de conteúdos, almejou-se, conforme Moreira e Massoni (2016), que os significados dos conteúdos fossem captados de forma crítica pelos aprendizes.

Dessa forma, cada vídeo, mediante as possibilidades de reorganização, avaliação e compartilhamento, tornou-se um Oaps, produzindo certa inferência com a captação crítica dos significados dos conteúdos.

\section{Estudantes em tempos de}

cibercultura e ciberespaço: produção

de vídeos colaborativos para o YouTube

Diante da realidade do ciberespaço, Lévy sinaliza que "o computador não é mais um centro, e sim um nó, um terminal, um componente da rede universal e calculante" (2010a, p. 45). De acordo com Lévy (2010a, 2010b, 2015), os processos tradicionais de aprendizagem tornaram-se, de certo modo, ultrapassados. Dentre os fatores que levam a essa constatação, destacam-se a necessidade de renovação dos saberes, a nova configuração do mundo do trabalho e o ciberespaço, que suporta tecnologias intelectuais que amplificam, exteriorizam e modificam numerosas funções cognitivas humanas.

Assim, esse terminal permitiu uma combinação de vários dispositivos e interfaces interativos, favorecendo uma construção colaborativa. Destacam-se o correio eletrônico, as conferências eletrônicas, o hiperdocumento compartilhado e os sistemas avançados de aprendizagem ou de trabalho cooperativo. De certo modo, Lévy (2010b) antecipou a natureza coautoral das mídias sociais presentes na web 2.0, ou seja, a web participativa, cuja natureza também pode ser aplicada e desenvolvida a partir de postagens nos canais do YouTube.

Além disso, o YouTube oportuniza os meios para o compartilhamento de vídeos, conforme Burgess e Green (2008), tornando-se um patrocinador da criatividadecoletiva, estimulando a participação de uma grande quantidade de criadores de conteúdo. Cabe ressaltar que

[...] o YouTube fornece os mecanismos de apoio e restrição de um sistema cujo significado é gerado pelos próprios usos, em que, coletivamente, os usuários exercem agência (BURGESS; GREEN, 2008, p. 2).

A produção e a distribuição de mídia alternativa, segundo Jenkins (2008), estimularam novas atividades e possibi- 
lidades de expressão. Desse modo, para Walczik (2008), o YouTube é um portal que se encontra dentro do conceito da web 2.0, ou seja, da internet participativa.

Uma vez observados os dados União Internacional de Telecomunicações (UIT), a tendência é que essa forma de mídia prolifere ainda mais. De acordo com a nona edição do relatório de final da UIT, de novembro de 2017, Medindo a Sociedade da Informação (MIS), podem-se observar dados e fazer a análise do uso das tecnologias da informação e comunicações(TICs) de 176 países. O Brasil encontra-se em $66^{\circ}$ lugar entre os países pesquisados e em $10^{\circ}$ entre os 35 países das Américas e Caribe, atrás, por exemplo, dos Estados Unidos, do Canadá, do Uruguai, da Argentina, do Chile e da Costa Rica.

Percebe-se também, no relatório, que o maior ganho do Brasil foi no indicador habilidades dos usuários em TICs, passando do $92^{\circ}$ para o $71^{\circ}$ lugar. No entanto, o Brasil piorou seu desempenho no indicador uso, pois foi do $56^{\circ}$ para o $57^{\circ}$ lugar. Também houve mudança no indicador acesso, passando da $79^{\mathrm{a}}$ para a $80^{\mathrm{a}}$ posição. Quanto à internet, comparando 2016 com 2017, o Brasil teve aumento na proporção de usuários de internet, de $58,3 \%$ para $59,7 \%$; aumento de assinantes de banda larga fixa, de $12,2 \%$ para 13\%; e aumento de banda larga móvel, de $88,6 \%$ para $89,5 \%$.
De acordo com a Organização das Nações Unidas no Brasil (2017a, 2017b), $48 \%$ da população mundial já utilizam internet. A proporção aumenta para $71 \%$, entre as pessoas de 15 a 24 anos. Além disso, em países desenvolvidos, 94\% dos jovens utilizam internet; enquanto nos países em desenvolvimento, o percentual é de $67 \%$; e de apenas $30 \%$ nos países menos desenvolvidos.

Os dados fornecidos pelo próprio YouTube, em "YouTube em números", apontam que há mais de um bilhão de usuários, representando quase um terço dos usuários da internet. Por sua vez, este espaço gera bilhões de horas de vídeos e de visualizações. Além disso, mais da metade dessas visualizações é realizada em dispositivos móveis. Assim, ao se realizar upload de vídeos, visualizações, discussões e comentários, os usuários e, também, participantes do "participa do YouTube" criam uma rede de prática criativa e acabam por produzir um mundo da arte especificamente voltado a essa mídia (BURGESS; GREEN, 2009).

Contudo, essa participação necessita ser melhor explorada, pois, no momento em que se oportuniza aos usuários que também sejam produtores de materiais ao invés de simples consumidores, certos cuidados precisam ser observados quanto à qualidade técnica, aos conteúdos, às referências e aos direitos autorais. Diante disso, para que cada um dos materiais produzidos na forma de vídeo 
pudesse ser acessado com facilidade e ficasse à disposição dos estudantes e da comunidade em geral, foi criado o canal As Várias Matemáticas.

\section{papel do professor nos processos de ensino e de aprendizagem}

A relação que outrora se dava apenas entre professor e aluno passou a contar também com o computador. Ele pode ser utilizado apenas como um meio, contudo, uma vez que se explore suas potencialidades, como consultas à internet, seu papel ramifica-se e é proporcionalmente intensificado.

O professor, nesse caso, passa a ser um mediador da aprendizagem, estabelecendo uma mediação pedagógica entre estudante e tecnologia. De acordo com Masetto (2000), a mediação pedagógica pode ser entendida como uma atitude ou um comportamento em que o professor se coloca como facilitador ou motivador da aprendizagem; como um profissional

que se apresenta com a disposição de ser uma ponte entre o aprendiz e sua aprendizagem - não uma ponte estática, mas uma ponte "rolante", que ativamente colabora para que o aprendiz chegue aos seus objeti$\operatorname{vos}(2000$, p. 144- 145).

Esse mesmo professor precisa observar e acompanhar a formação de estudantes que fazem uso do computador e navegam interativamente no ciberespaço. Essa formação envolve transformações perceptivo-cognitivas, torna os estudantes leitores imersivos e faz com que eles construam roteiros não lineares e não sequenciais (SANTAELLA 2004).

Esta nova realidade na sala de aula, do uso do computador e do acesso à internet cada vez mais facilitados pela atualização dos sistemas de telefonia móvel, exige uma atitude de parceria e de corresponsabilidade entre professor e alunos, com o propósito de desenvolver o processo de aprendizagem para fortalecê-lo. $\mathrm{O}$ docente deve estar preparado para essa realidade; assim, ambos, professor e alunos, buscam trabalhar em conjunto, como uma equipe, para atingir objetivos em comum (MASETTO, 2003).

Enfim, a questão da didática também deve ser constantemente repensada. A organização das atividades desenvolvidas em sala de aula reflete diretamente na aprendizagem dos estudantes. Gil (2010) aponta para alguns desafios que o docente enfrenta na contemporaneidade e destaca que, para minimizá-los, o professor necessita dispor de conhecimentos técnicos e de visão do futuro e ser um mediador do processo de aprendizagem.

Também se espera que o professor seja capaz de gerar sua própria formação contínua, seja transformador, multicultural, intercultural, reflexivo, aberto. Seja capaz de trabalhar em equipe, de 
enfrentar os deveres e os dilemas éticos da profissão e de utilizar novas tecnologias.

\section{Resultados parciais}

Até o presente momento, alguns apontamentos podem ser considerados a partir dos questionários aplicados aos estudantes.

Primeiramente, metade da turma não conhecia nada sobre elaboração de vídeos e os que conheciam, na sua maioria, haviam realizado atividades com o mesmo professor em momentos anteriores.

Quanto aos conteúdos explorados, eles envolviam principalmente integrais e derivadas, ou seja, justamente os conteúdos que os alunos apresentaram como os mais difíceis. Segundo os estudantes, esses assuntos foram escolhidos por serem os principais na disciplina. As questões surgiram a partir de três fontes, a saber: do próprio caderno, a partir de exercícios resolvidos pelo professor; de livros da bibliografia da disciplina; e de criações, a partir do que foi estudado.

Dentre as maiores dificuldades apontadas, destacaram-se: falta de afinidade para trabalhar em equipe, pois nem todos os estudantes se reuniram para contribuir com proposta, e falta de clareza nas explicações, como comprovam os depoimentos dos próprios estudantes:
"Um pouco de dificuldade, como escolhemos gravar uma pessoa falando, muitas vezes tivemos que refazer gravações por causa de erros ou falta de atenção [...] na execução da parte da gravação e elaboração do conteúdo"; "Algumas das dificuldades encontradas para a elaboração do mesmo foram planejar a melhor forma de realizar as explicações, de modo que a pessoa que fosse assistir conseguisse compreender o que estava sendo explicado, além da execução e gravação do mesmo". Os grupos se reuniram, para realizar a proposta, nos domicílios dos estudantes e em espaços da instituição, como a biblioteca.

A partir da análise dos vídeos produzidos, os estudantes apontaram, principalmente, a necessidade de melhora na edição e na organização dos conteúdos apresentados. Isso pode ser observado no Gráfico 1, que comporta, até o momento, um resumo da avaliação feita pelos alunos, considerando os vídeos produzidos a partir da proposta. 
Gráfico 1 - Resumo percentual de alguns tópicos da avalição dos vídeos produzidos

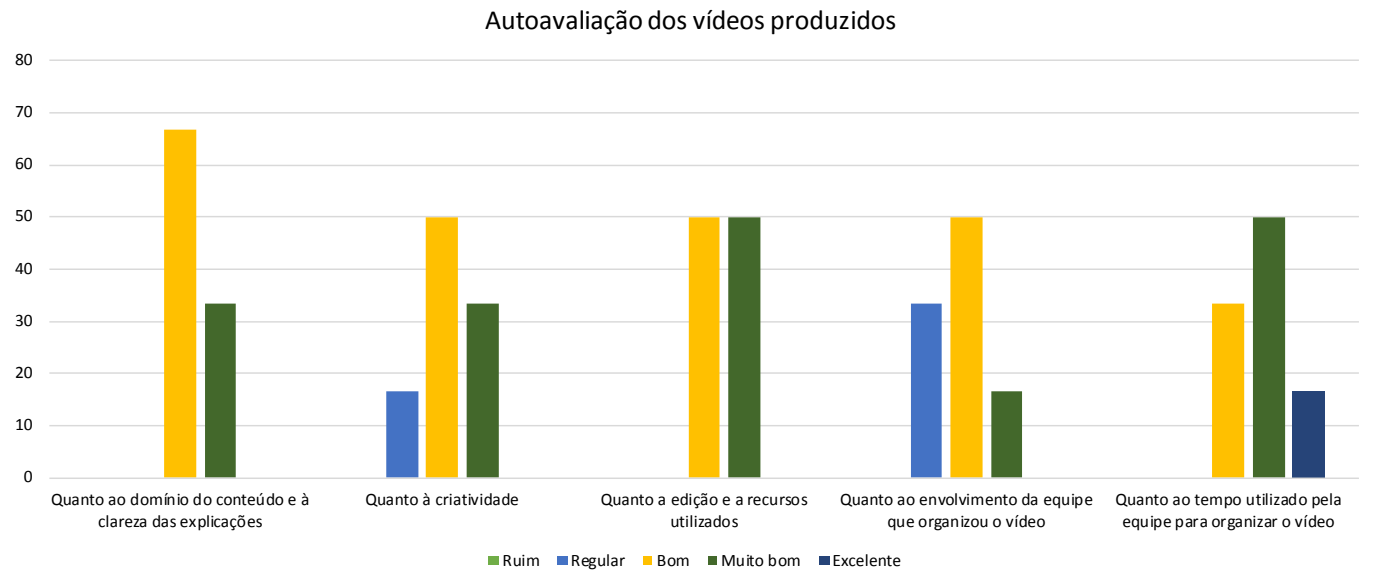

Fonte: autores.

\section{Considerações finais}

Após várias semanas de atividades desenvolvidas com a turma em foco, foi possível chegar a algumas considerações parciais sobre o desenvolvimento da proposta. A primeira delas diz respeito ao envolvimento dos estudantes e a sua percepção quanto à aprendizagem; a segunda, ao papel do professor; e a terceira, ao uso da tecnologia.

Os estudantes aderiram à proposta e desenvolveram um trabalho integrado com a disciplina. A qualidade dos trabalhos desenvolvidos se mostrou coerente com a participação dos estudantes e com o envolvimento com a proposta. Alguns grupos se dedicaram de forma mais assídua, enquanto outros trataram a proposta apenas como mais um trabalho a ser realizado.
Coube ao professor valorizar todos os trabalhos apresentados, gerar discussões para trabalhos futuros e sugerir possíveis melhorias. O professor atuou como mediador da proposta do início ao fim, auxiliando nas partes conceitual e técnica, mas respeitando a autonomia dos estudantes enquanto esses desenvolviam seus materiais. Isso aproximou estudantes e professor.

Cada vídeo se configurou como um Oaps, uma vez que, como objeto de aprendizagem, procurou desenvolver características pertinentes, brevemente apresentadas neste texto. Os vídeos se mostraram uma forma de explorar potencialmente os conteúdos da disciplina de Cálculo II, influenciando, consequentemente, na aprendizagem dos estudantes. Além disso, esse processo de trabalho está em andamento e terá 
continuidade nos próximos semestres, quando a produção realizada pelo grupo de estudantes em foco for analisada, avaliada e aprimorada por estudantes de outras turmas. Percebeu-se que as tecnologias necessitam ser mais exploradas, pois os estudantes ainda são muito passivos, ou seja, portam-se mais como consumidores de informação e menos como autores de um processo que visa à produção de conhecimento.

\section{Videos as an object of potentially meaningful learning}

\section{Abstract}

This work is about producing videos as Potentially Significant Learning Objects (PSLO), later posted to a YouTube channel, managed by the students themselves. It aims to point and reflect methodological alternatives to include students in the process of Teaching and Learning. The study is set up as a case study involving students from a Calculus class of an institution of Higher Education. It is noteworthy that the proposal remains in development and so far it has been possible to perceive that students behave as information consumers and to a lesser extent as knowledge producers, with the teacher as mediator of the process.

Keywords: Learning objects.Meaningful learning. Videos.

\section{Referências}

AGUIAR, E. B. A.; FLÔRES, M. L. P. Objetos de aprendizagem: conceitos básicos. In: TAROUCO, L. M. R. et. al. (Org.). Objetos de aprendizagem: teoria e prática. Porto Alegre: Evangraf, 2014. p. 14-15.

AUDINO, D.; NASCIMENTO, R. Objetos de aprendizagem: diálogos entre conceitos e uma nova proposição aplicada à educação. Revista Contemporânea de Educação, Rio de Janeiro, v. 5, p. 128-148, 2010. Disponível em: <https://revistas.ufrj.br/index.php/rce/article/ view/1620>. Acesso em: 18 out. 2017.

AUSUBEL, D. P. The psychology of meaningful verbal learning. Grune and Stratton: New York, 1963.

BOGDAN, R. C.; BIKLEN, S. K. A investigação qualitativa em educação. Porto, Portugal: Porto, 1994.

BRAGA, J. C. (Org.) Objetos de aprendizagem, volume 1: introdução e fundamentos. Santo André: Editora da UFABC, 2014.

BURGESS, J.; GREEN, J. Agency and controversy in the YouTube community. in PROCEEDINGS IR 9.0: rethinking communities, rethinking place - association of internet researchers (AoIR) conference, IT University of Copenhagen, Denmark, 2008.

YouTube e a Revolução Digital: como o maior fenômeno da cultura participativa transformou a sociedade. São Paulo: Aleph, 2009.

GIL, A. C. Didática do Ensino Superior. São Paulo: Atlas, 2010.

JENKINS, H. What happened before YouTube? 2008. Disponível em: <http://henryjenkins. org/2008/06/what_happened_before_youtube. html>. Acesso em: 25 nov. 2017.

LÉVY, P. A inteligência coletiva: por uma antropologia do ciberespaço. 10. ed. São Paulo: Edições Loyola, 2015. 
As tecnologias da inteligência: o futuro do pensamento na era da informática. 2. ed. São Paulo: Editora 34, 2010a.

Cibercultura. Trad. Carlos Irineu da Costa. São Paulo: Editora 34, 2010b.

MASETTO, M. T. Competência pedagógica do professor universitário. São Paulo: Summus, 2003.

Mediação Pedagógica e o uso da tecnologia. In: MORAN, J. M.; MASETTO, M. T.; BEHRENS, M. A. Novas tecnologias e mediação pedagógica. 10. ed. Campinas: Papirus, 2000. p. 133-173.

MORAES, R.; GALIAZZI, M. C. Análise textual discursiva. 2. ed. Ijuí: Unijuí, 2013.

MOREIRA, M. A.; MASSONI, N. M. Noções básicas de epistemologias e teorias de aprendizagem como subsídios para a organização de sequências de ensino-aprendizagem em ciências / física. São Paulo: Livraria da Física, 2016.

ORGANIZAÇÃO DAS NAÇÕES UNIDAS NO BRASIL. Brasil ocupa $66^{\circ}$ lugar em ranking $d a$ ONU de Tecnologia de Informação e Comunicação. 2017a. Disponível em: <https://nacoesunidas.org/agencias/uit/>. Acesso em: 25 nov. 2017.

. Mais de 4 bilhões de pessoas terão acesso à internet móvel até o fim de 2017, diz relatório da ONU. 2017b. Disponível em: <https:// nacoesunidas.org/agencias/uit/>. Acesso em: 25 nov. 2017.

SANTAELLA, L. Navegar no ciberespaço: o perfil cognitivo o leitor imersivo. São Paulo: Paulus, 2004. (Coleção Comunicação).

TAROUCO, L. M. R. et. al. (Org.). Objetos de aprendizagem: teoria e prática. Porto Alegre: Evangraf, 2014.

WALCZYK, T. Google video: just another video sharing site? Journal of Library Administration, Philadelphia, v. 47, p. 175-181, 2008.
WILEY, D. Connecting learning objects to instructional design theory: a definition, a metaphor, and a taxonomy. In: WILEY, David (Ed.). The Instructional Use of Learning $\mathrm{Ob}$ jects. 2000. Disponível em: <http://reusability. org/read/chapters/wiley.doc>. Acesso em: 10 ago. 2017.

YOUTUBE. YouTube em números. 2017. Disponível em: <https://www.youtube.com/intl/pt-BR/ yt/about/press/>. Acesso em: 25 nov. 2017. 